\title{
FIXED POINT RESULTS FOR CONTRACTIVE MAPPINGS IN COMPLEX VALUED FUZZY METRIC SPACES
}

\author{
SATISH SHUKLA*, ROSANA RODRÍGUEZ-LÓPEZ** AND MUJAHID ABBAS*** \\ * Department of Applied Mathematics \\ Shri Vaishnav Institute of Technology \& Science \\ Gram Baroli, Sanwer Road, Indore (M.P.) 453331, India \\ E-mail: satishmathematics@yahoo.co.in \\ **Departamento de Estatística, Análise Matemática e Optimización \\ Facultade de Matemáticas \\ Universidade de Santiago de Compostela, 15782, Spain \\ E-mail: rosana.rodriguez.lopez@usc.es \\ *** Department of Mathematics, Government College University \\ Katchery Road, Lahore 54000, Pakistan \\ and \\ Department of Mathematics, King Abdulaziz University \\ P.O. Box 80203, Jeddah 21589, Saudi Arabia \\ E-mail: abbas.mujahid@gmail.com
}

\begin{abstract}
The aim of this paper is to introduce the notion of complex valued fuzzy metric spaces. We prove some fixed point results of contractive mappings on complex valued fuzzy metric spaces. Some examples are presented to support the results proved herein. Our results extend various results in the existing literature.

Key Words and Phrases: Complex valued $t$-norm, complex valued fuzzy set, complex valued fuzzy metric space, fixed point.
\end{abstract}

2010 Mathematics Subject Classification: 54H25, 45H10.

Acknowledgements. We are grateful to the Editors in Chief Professor Ioan A. Rus and Professor Adrian Petrussel and the reviewers for their interesting comments on this paper.

The research of R. Rodríguez-López was partially supported by Ministerio de Economía y Competitividad, projects MTM2013-43014-P and MTM2016-75140-P, and co-financed by the European Community fund FEDER.

\section{REFERENCES}

[1] A. Azam, B. Fisher, M. Khan, Common fixed point theorems in complex valued metric spaces, Numer. Funct. Anal. Optim., 32(2011), no. 3, 243-253.

[2] F. Castro-Company, Fuzzy quasi-metric spaces: bicompletion, contractions on product spaces, and applications to access predictions, Ph.D. Thesis, Universidad Politécnica de Valencia, 2010. 
[3] F. Castro-Company, S. Romaguera, Experimental results for information systems based on accesses locality via intuitionistic fuzzy metrics, The Open Cybernetics \& Systemics Journal, 2(2008), 158-172.

[4] F. Castro-Company, S. Romaguera, P. Tirado, Application of the Banach fixed point theorem on fuzzy quasi-metric spaces to study the cost of algorithms with two recurrence equations, in: Proceedings of the International Conference on Fuzzy Computation and 2nd International Conference on Neural Computation (ICFC), 2010, 105-109.

[5] M.S. El Naschie, On the unification of the fundamental forces and complex time in the space, Chaos Solitons \& Fractals, 11(2000), 1149-1162.

[6] A. George, P. Veeramani, On some results in fuzzy metric spaces, Fuzzy Sets and Systems, 64(1994), 395-399.

[7] A. George, P. Veeramani, On some results of analysis for fuzzy metric spaces, Fuzzy Sets Systems, 90(1997), 365-368.

[8] M. Grabiec, Fixed points in fuzzy metric spaces, Fuzzy Sets and Systems, 27(1988), 385-389.

[9] V. Gregori, A. Sapena, On fixed-point theorems in fuzzy metric spaces, Fuzzy Sets and Systems, 125(2002), 245-252.

[10] V. Gregori, S. Morillas, A. Sapena, Examples of fuzzy metrics and applications, Fuzzy Sets and Systems, 170(2011), 95-111.

[11] I. Kramosil, J. Michalek, Fuzzy metric and statistical metric spaces, Kybernetica, 15(1975), 326-334.

[12] A. Mejias, L.D.G. Sigalotti, E. Sira, F. De Felice, On El Naschie's complex time, Hawking's imaginary time and special relativity, Chaos Solitons \& Fractals, 19(2004), no. 4, 773-777.

[13] S. Morillas, A. Sapena, Fuzzy metrics and color image filtering, XVI Encuentro de Topología, Almería, Spain, 2009

[14] J.J. Nieto, R. Rodríguez-López, Contractive mapping theorems in partially ordered sets and applications to ordinary differential equations, Order, 22(2005), 223-239.

[15] G.O. Okeng'o, J.B. Awuor, On the complexification of Minkowski spacetime, Africa J. Physical Sciences, 2(2015), 73-76.

[16] S. Romaguera, A. Sapena, P. Tirado, The Banach fixed point theorem in fuzzy quasi-metric spaces with application to the domain of words, Topology Appl., 154(2007), 2196-2203.

[17] L.D.G. Sigalotti, O. Rendón, Quantum decoherence and El Naschie's complex temporality, Chaos Solitons \& Fractals, 32(2007), 1611-1614.

[18] R. Vasuki, P. Veeramani, Fixed point theorems and Cauchy sequences in fuzzy metric spaces, Fuzzy Sets and Systems, 135(2003), 415-417.

[19] L.A. Zadeh, Fuzzy sets, Inform. Control, 8(1965), 338-353.

Received: September 17, 2015; Accepted: March 17, 2016. 
